\title{
HUBUNGAN ANTARA INDEKS MASSA TUBUH KORBAN DENGAN KASUS KEMATIAN MENDADAK YANG DIPERIKSA DI INSTALASI KEDOKTERAN FORENSIK RSUP Dr. SARDJITO YOGYAKARTA TAHUN 2011 - 2015
}

\section{Relationship between Body Mass Index Victim with Sudden Death Cases Examined in Forensic Installation Unit RSUP Dr. Sardjito Yogyakarta Hospital from 2011 - 2015}

\author{
Adji Suwandono' ${ }^{1)}$, Hendro Widagdo ${ }^{2)}$, Suhartini ${ }^{3)}$ \\ ${ }^{*}$ Bagian Forensik \& Medikolegal, FK, Universitas Sebelas Maret \\ e-mail: adji.suwandono@staff.uns.ac.id
}

\begin{abstract}
ABSTRAK
Latar Belakang: Kurangnya olahraga dan banyaknya asupan makanan berlemak dapat menyebabkan obesitas dimana memberikan kontribusi pada penyebab kematian mendadak yang tak terduga dan berhubungan dengan indeks massa tubuh. Tujuan penelitian ini adalah mengetahui hubungan antara indeks massa tubuh dengan kasus kematian mendadak yang ditangani di RSUP Dr. Sardjito tahun 2011 - 2015 dengan cara menghitung seluruh data panjang badan dan berat badan pada kasus kematian mendadak yang ditangani di RSUP Dr. Sardjito Yogyakarta tahun 2011 - 2015.

Metode: Penelitian ini merupakan penelitian observasi analitik dengan pengambilan data secara cross sectional karena sampel dan semua variabel diambil dalam satu periode waktu. Data yang digunakan adalah data sekunder, khususnya dari visum et. Repertum Instalasi Kedokteran Forensik RSUP Dr. Sardjito Yogyakarta.

Hasil: Penelitian ini menunjukkan indeks massa tubuh dengan berat badan lebih sangat mendominasi jumlah kasus kematian mendadak sebanyak $82.25 \%$ dibandingkan berat badan normal ataupun berat badan kurang. Orang dengan berat badan lebih memiliki risiko 13.05 kali lebih besar untuk mengalami serangan penyakit kardiovaskuler yang merupakan penyebab utama kematian mendadak.

Kesimpulan: Terdapat hubungan antara indeks massa tubuh korban dengan kasus kematian mendadak yang diperiksa di Instalasi Kedokteran Forensik RSUP Dr. Sardjito Yogyakarta Tahun $2011-2015$.
\end{abstract}

Kata kunci: Indeks Massa Tubuh, Kematian Mendadak, RSUP Dr. Sardjito Yogyakarta 


\begin{abstract}
Background: Lack of exercise and a high intake of fatty foods may lead to obesity contributing to the unexpected cause of sudden death, also related to body mass index. Body mass index is the value taken from the calculation of a person's body weight and body height. The purpose of this study is to know the relationship between body mass index and sudden death cases handled in RSUP Dr. Sardjito Yogyakarta from 2011 - 2015 by calculating all data of body length and body weight in case of sudden death which handled in RSUP Dr. Sardjito Yogyakarta from 2011 - 2015.

Method: This study is an analytic observation research with cross sectional data collection because the sample and all variables are taken in one time period. The data used are secondary data, especially from visum et. Repertum Forensic Installation Unit RSUP Dr. Sardjito Yogyakarta. The target populations of this study are all cases of sudden death in Yogyakarta. Accessible populations are sudden death cases handled at Forensic Installation Unit RSUP Dr. Sardjito Yogyakarta from 2011-2015.

Results: This study shows that body mass index with body weight more dominates the number of cases of sudden death as much as $82.25 \%$ compared to normal weight or underweight. People who weigh more than 13.05 times are more likely to experience cardiovascular disease, which is the main cause of sudden death.

Conclusion: There is a relationship between casualty body mass index and sudden death cases examined at Forensic Installation Unit RSUP Dr. Sardjito Yogyakarta from 20112015.
\end{abstract}

Keyword: Body Mass Index, RSUP Dr. Sardjito Yogyakarta, Sudden Death

PENDAHULUAN

Kematian mendadak akibat penyakit seringkali mendatangkan kecurigaan baik bagi penyidik, masyarakat, atau keluarga, khususnya bila yang meninggal adalah orang yang cukup dikenal oleh masyarakat, orang yang meninggal di rumah tahanan dan ditempat-tempat umum seperti: hotel, cottage, terminal, motel, atau di dalam kendaraan. Kecurigaan adanya unsur kriminal pada kasus kematian mendadak terutama disebabkan masalah TKP (Tempat Kejadian Perkara) yaitu bukan di rumah korban atau di rumah sakit, melainkan di tempat umum. Karena alasan tersebut kematian mendadak termasuk kasus forensik walaupun hasil otopsinya menunjukan kematian diakibatkan oleh misalnya penyakit jantung coroner atau perdarahan otak misalnya ${ }^{[1]}$.

Penentuan sebab kematian menjadi penting terkait dengan kepentingan hukum, perubahan status almarhum dan keluarganya, serta hak dan kewajiban yang timbul dari meninggalnya orang tersebut.
Autopsi sebagai suatu jalan penentuan sebab kematian merupakan pilihan solusi saat berhadapan dengan suatu kematian mendadak. Sebuah penelitian di Afrika Selatan pada kasus kematian mendadak mengungkapkan bahwa 97\% dari kasuskasus yang dianggap "alami" adalah penyebab mayoritas pada orang dewasa baik kardiovaskular, pernapasan, atau sistem saraf pusat. Penyakit jantung iskemik adalah penyebab paling umum kematian mendadak pada populasi total ${ }^{[2]}$.

Studi lain di Italia menunjukkan bahwa dari semua kasus kematian mendadak pada tahun 2001-2005 ditemukan 155 kasus, 100 kasus disebabkan oleh karena penyakit kardiovaskular. Institut Nasional Penelitian dan Pengembangan Departemen Kesehatan di Indonesia melaporkan bahwa persentase kematian mendadak meningkat dari 5.9\% (1975) ke 9.1\% (1981), $16.0 \%$ (1986), dan $19.0 \%(1995)^{[1]}$. Sampai saat ini, belum ada penelitian yang mencari hubungan langsung antara indeks massa tubuh (IMT) dan kematian menda- 
dak, yaitu kematian alami tak terduga yang terjadi seketika atau hingga maksimal dari dua puluh empat jam setelah timbulnya gejala ${ }^{[1]}$.

\section{SUBJEK DAN METODE}

Penelitian ini menggunakan desain observasi analitik dengan pengambilan data secara cross sectional karena sampel dan semua variabel diambil dalam satu periode waktu $^{[3]}$. Penelitian dilakukan dengan pengambilan data visum et repertum kasus kematian mendadak di IKF Rumah Sakit Umum Pusat dr.Sardjito/ Fakultas Kedokteran Universitas Gadjah Mada Yogyakarta periode Januari 2011 sampai Desember 2015. Penelitian dilakukan pada Oktober 2017.

Seluruh data Visum et Repertum kasus kematian mendadak digunakan sebagai sampel, yaitu 62 kasus kematian mendadak. Adapun kriteria inklusi meliputi Visum et Repertum jenazah yang diklasifikasikan sebagai kasus kematian mendadak di IKF RSUP Dr. Sardjito Yogyakarta dari tahun 2011-2015. Kriteria eksklusi meliputi kasus kematian mendadak yang terdapat intoksikasi alkohol dan NAPZA.

Instrumen penelitian menggunakan naskah Visum et Repertum dari IKF RSUP Dr. Sardjito Yogyakarta dan daftar periksa yang semuanya terkumpul dalam naskah rekam medik yang disimpan di IKF RSUP Dr. Sardjito. Data yang dikumpulkan berupa nama, usia, jenis kelamin, waktu kematian, kondisi patologis umum, dan indeks massa tubuh.

\section{HASIL}

\section{Karakteristik Subyek Penelitian}

Subyek penelitian adalah data Visum Et Repertum kasus kematian mendadak dari Januari 2011 sampai dengan Desember 2015 yang memenuhi kriteria inklusi dan eksklusi didapatkan 62 kasus. Data-data tersebut kemudian diolah menjadi data profil berupa data-data persentase/ frekuensi kasus kematian mendadak yang diperiksa di IKF RSUP dr. Sardjito/ FK.UGM dari jumlah kasus, kasus berdasarkan usia, kasus berdasarkan jenis kelamin, waktu kematian, dan kondisi patologis umum.

Tabel 1. Jumlah Kasus Kematian Mendadak di IKF RSUP. Dr. Sardjito Tahun 2011-2015.

\begin{tabular}{lcc}
\hline Tahun & Jumlah Kasus & Persentase \\
\hline 2011 & 9 & $14.52 \%$ \\
2012 & 11 & $17.74 \%$ \\
2013 & 9 & $14.52 \%$ \\
2014 & 15 & $24.19 \%$ \\
2015 & 18 & $29.03 \%$ \\
Total & 62 & $100 \%$ \\
\hline
\end{tabular}

Sumber: Rekam Medik RSUP Dr. Sardjito

Tabel 2. Jumlah Kasus Kematian Mendadak di IKF RSUP. Dr. Sardjito Tahun 2011 - 2015 Berdasarkan Usia.

\begin{tabular}{|c|c|c|}
\hline Usia (tahun) & $\mathrm{n}$ & $\%$ \\
\hline $\begin{array}{l}\text { Dewasa Muda } \\
(18-40)\end{array}$ & 21 & $33.87 \%$ \\
\hline $\begin{array}{l}\text { Dewasa Setengah } \\
\text { Baya }(41-60)\end{array}$ & 21 & $33.87 \%$ \\
\hline $\begin{array}{l}\text { Dewasa Tua } \\
\text { (diatas 60) }\end{array}$ & 20 & $32.26 \%$ \\
\hline Total & 62 & 100 \\
\hline
\end{tabular}

Tabel 3. Jumlah Kasus Kematian Mendadak di IKF RSUP Dr. Sardjito Tahun 2011-2015 Berdasarkan Jenis Kelamin

\begin{tabular}{ccc}
\hline Tahun & Laki-Laki & Perempuan \\
\hline 2011 & $8(12.90 \%)$ & $1(1.61 \%)$ \\
2012 & $9(14.52 \%)$ & $2(3.23 \%)$ \\
2013 & $9(14.52 \%)$ & $0(0.00 \%)$ \\
2014 & $12(19.35 \%)$ & $3(4.84 \%)$ \\
2015 & $15(24.19 \%)$ & $3(4.84 \%)$ \\
\hline Total & $53(85.48 \%)$ & $9(14.52 \%)$ \\
\hline
\end{tabular}

Sumber: Rekam Medik RSUP Dr. Sardjito

Tabel 4. Waktu Kematian pada Kasus Kematian Mendadak di IKF RSUP. Dr. Sardjito Tahun $2011-2015$.

\begin{tabular}{lcc}
\hline Waktu Kematian & $\mathrm{n}$ & $\%$ \\
\hline $2-8$ jam & 16 & 25.80 \\
$8-12$ jam & 19 & 30.65 \\
$12-24$ jam & 23 & 37.10 \\
$>24$ jam & 4 & 6.45 \\
Total & 62 & 100 \\
\hline
\end{tabular}

Sumber: Rekam Medik RSUP Dr. Sardjito 
Tabel 5. Kondisi Patologis Umum pada Kasus Kematian Mendadak di IKF RSUP. Dr. Sardjito Tahun 2011 - 2015.

\begin{tabular}{lcc}
\hline \multicolumn{1}{c}{$\begin{array}{c}\text { Kondisi Patologis } \\
\text { Umum }\end{array}$} & $\mathrm{n}$ & $\%$ \\
\hline Asfiksia, Penyakit & 33 & 53.23 \\
Kardiovaskuler & 25 & 40.32 \\
Asfiksia, Penyakit & 4 & 6.45 \\
Kronis & & \\
Asfiksia, Tanpa & & \\
Penyakit & & \\
\hline \multicolumn{1}{c}{ Total } & 62 & 100 \\
\hline
\end{tabular}

Sumber: Rekam Medik RSUP Dr. Sardjito

\section{Analisis Univariat}

Tabel 6. Indeks Massa Tubuh pada Kasus Kematian Mendadak di IKF RSUP. Dr. Sardjito Tahun $2011-2015$.

\begin{tabular}{lcc}
\hline \multicolumn{1}{c}{ Indeks Massa Tubuh } & $\mathrm{n}$ & $\%$ \\
\hline Kurang $(<18.5)$ & 2 & 3.23 \\
Normal $(18.5-22.9)$ & 9 & 14.52 \\
Lebih $(>23.0)$ & 51 & 82.25 \\
$\quad$ Total & 62 & 100 \\
\hline
\end{tabular}

Sumber: Rekam Medik RSUP Dr. Sardjito

\section{Analisis Bivariat}

Tabel 7. Hasil Uji Analisis Chi-Square Indeks Massa Tubuh dengan Penyakit Kardiovaskular pada Kasus Kematian Mendadak

\begin{tabular}{lccccc}
\hline \multicolumn{1}{c}{ Indeks Massa Tubuh } & $\begin{array}{c}\text { Penyakit Kardiovaskular } \\
\text { Tidak }\end{array}$ & Ya & Total & OR & p \\
\hline Normal & 9 & 5 & 14 & & \\
Berlebih & 4 & 29 & 33 & 13.05 & 0.001 \\
Jumlah & 13 & 34 & 47 & & \\
\hline
\end{tabular}

Sumber: Data primer

\section{PEMBAHASAN}

Harus diperhitungkan bahwa dalam kasus kematian mendadak yang ditemukan di IKF RSUP Dr. Sardjito dari tahun 20112015, kurang dari setengahnya dilakukan pemeriksaan luar dan dalam terutama karena permintaan keluarga. Walaupun sebenarnya alasan utama dilakukan autopsi pemeriksaan luar dan dalam adalah untuk mengetahui penyebab kematian. Inilah sebabnya mengapa judul penelitian adalah "hubungan" dan bukan "pengaruh" karena kurang dari setengah dari total kasus dilakukan pemeriksaan luar dan dalam (autopsi).

Berdasarkan penelitian yang telah dilakukan, didapatkan hasil bahwa kasus kematian mendadak dengan korban memiliki IMT berat badan lebih mempunyai jumlah yang paling besar dibandingkan yang berat badan kurang maupun berat badan normal. Hal ini menunjukkan bahwa IMT dan faktor resiko penyakit kardiovaskular serta penyakit kronis lainnya menjadi penyebab utama karena hasil akhir yang terjadi pada pasien dalam lebih kurang 24 jam kematiannya adalah asfiksia sebagai mekanisme kematian yang dapat dilihat dengan memeriksa tanda-tanda sianosis secara eksternal.

Otopsi dapat memberikan informasi berharga mengenai penyebab kematian terutama bagi keluarga karena bisa jadi penyakit yang dapat diwariskan namun masih merupakan tugas yang sulit dilakukan dengan baik untuk kebanyakan dokter forensik. Apalagi kaitannya dengan indeks massa tubuh seseorang, dimana nilai indeks massa tubuh juga berhubungan dengan banyak faktor lainnya, seperti usia, jenis kelamin, genetik, gaya hidup terutama pola makan, dan aktivitas fisik.

Penelitian $^{[3]}$ menunjukkan bahwa terdapat hubungan yang signifikan antara usia yang lebih tua dengan IMT kategori obesitas. Subjek penelitian pada kelompok usia 40-49 dan 50-59 tahun memiliki risiko lebih tinggi mengalami obesitas dibandingkan kelompok usia kurang dari 40 tahun. Keadaan ini dicurigai oleh karena lambatnya proses metabolisme, berkurangnya aktivitas fisik, dan frekuensi konsumsi pangan yang lebih sering ${ }^{[4]}$. 
IMT dengan kategori kelebihan berat badan lebih banyak ditemukan pada laki-laki. Namun, angka kejadian obesitas lebih tinggi pada perempuan dibandingkan dengan laki-laki. Data dari National Health and Nutrition Examination Survey (NHANES) periode 1999-2000 menunjukkan tingkat obesitas pada laki-laki sebesar $27.3 \%$ dan pada perempuan sebesar $30.1 \%$ di Amerika ${ }^{[5]}$.

Penelitian terdahulu menunjukkan bahwa lebih dari $40 \%$ variasi IMT dijelaskan oleh faktor genetik. IMT sangat berhubungan erat dengan generasi pertama keluarga. Studi lain yang berfokus pada pola keturunan dan gen spesifik telah menemukan bahwa $80 \%$ keturunan dari dua orang tua yang obesitas juga mengalami obesitas dan kurang dari $10 \%$ memiliki berat badan normal ${ }^{[6]}$.

Pola makan adalah pengulangan susunan makanan yang terjadi saat makan. Pola makan berkenaan dengan jenis, proporsi dan kombinasi makanan yang dimakan oleh seorang individu, masyarakat atau sekelompok populasi. Makanan cepat saji berkontribusi terhadap peningkatan indeks massa tubuh sehingga seseorang dapat menjadi obesitas. Hal ini terjadi karena kandungan lemak dan gula yang tinggi pada makanan cepat saji. Selain itu peningkatan porsi dan frekuensi makan juga berpengaruh terhadap peningkatan obesitas. Orang yang mengkonsumsi makanan tinggi lemak lebih cepat mengalami peningkatan berat badan dibanding mereka yang mongkonsumsi makanan tinggi karbohidrat dengan jumlah kalori yang sama $^{[6]}$.

Aktifitas fisik menggambarkan gerakan tubuh yang disebabkan oleh kontraksi otot menghasilkan energi ekspenditur. Menjaga kesehatan tubuh membutuhkan aktifitas fisik sedang atau bertenaga serta dilakukan hingga kurang lebih 30 menit setiap harinya dalam seminggu. Penurunan berat badan atau pencegahan peningkatan berat badan dapat dilakukan dengan beraktifitas fisik sekitar 60 menit dalam sehari $^{[6]}$.
Analisis statistik yang dilakukan pada penelitian ini adalah uji analisis Chi Square dengan tingkat kepercayaan sebesar 95\% didapatkan nilai odds ratio 13.05, sehingga dapat disimpulkan korban dengan indeks massa tubuh terklasifikasi berat badan lebih mempunyai resiko 13.05 kali lebih besar untuk mengalami serangan penyakit kardiovaskular yang mematikan, penyebab utama kasus kematian mendadak.

\section{SIMPULAN DAN SARAN}

Jumlah kematian mendadak yang ditemukan sebanyak 62 kasus. Berdasarkan jenis kelamin, korban laki-laki lebih banyak daripada perempuan. Indeks massa tubuh dengan berat badan lebih sangat mendominasi jumlah kasus kematian mendadak sebanyak $82.25 \%$ dibandingkan berat badan normal ataupun berat badan kurang. Ada hubungan antara indeks massa tubuh korban dengan kasus kematian mendadak yang diperiksa di RSUP Dr. Sardjito Yogyakarta tahun 2011-2015, korban dengan berat badan lebih mempunyai risiko 13.05 kali lebih besar untuk mengalami serangan penyakit kardiovaskuler yang merupakan penyebab utama kematian mendadak.

\section{DAFTAR PUSTAKA}

1. Tiemensma M, Burger E (2012). Sudden and Unexpected Deaths in an adult population, Cape Town, South Africa, 2001-2005. Vol. 102, no. 2, pp. 90.

2. Hakim FA (2010). Aspek Medikolegal Kematian Mendadak Akibat Penyakit (Natural Sudden Death) diakses pada 30 Juni 2017 ,

URL:https://rludifkunjani.wordpress.c om/2010/11/17/aspek-medikolegalkematian-mendadak-akibat-penyakitnatural-sudden-death/

3. Kantachuvessiri A, Sirivichayakul C, KaewKungwal J, Tungtrongchitr R, Lotrakul M (2005). Factors Associated with Obesity among 
Workers in a Metropolitan. Southeast Asian J Trop Med Public Health. 2005; 36:1057-65.

4. National Health and Nutrition Examination Survey (ENHANES) (2007). Anthropometry Procedures Manual. USA : CDC.
5. Gayle M, Galletta MD (2005). Obesity :Obesity Causes Symptoms, Treatment.

http://www.emedicinehealth.com/obe sity/page2_em.htm\#Obesity\%20CaDi akses pada 17 September 2017. 